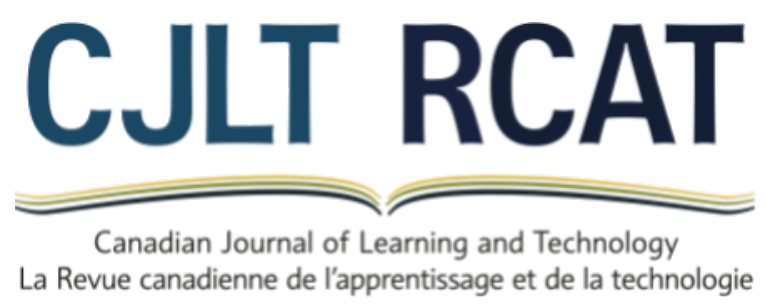

Volume 47 (4)

Special Issue 2021

\title{
Safe and Responsible Internet Use in a Connected World: Promoting Cyber- Wellness
}

\section{Utilisation sécuritaire et responsable de l'Internet dans un monde connecté : Promouvoir le cyber-bien-être}

Cathy Lewin, Manchester Metropolitan University, UK

Dale Niederhauser, West Virginia University, USA

Quinn Johnson, Universite Laval, Canada

Toshinori Saito, Seisa University, Japan

Akira Sakamoto, Ochanomizu University, Japan

Roger Sherman, Cambodia Foundation for Higher Education, USA

\begin{abstract}
Cyber-wellness concerns positive wellbeing in online spaces, including awareness of how to behave appropriately and protect oneself. In this paper the complex nature of cyber-wellness, focusing on four key aspects, is explained and illustrated. Firstly, developing students' information and media literacy skills is essential for promoting cyber-wellbeing. Such skills are also required for supporting democratic participation. Secondly, the threats and challenges to young people's cyberwellbeing are identified and discussed, arguing for the need to develop digital resilience. Thirdly, the role of policy at macro-, meso-, and micro-levels are discussed and how policy and educational practitioners can promote cyber-wellness awareness, knowledge and strategies. This paper provides a review of the limited scholarship on cyber-wellness education and highlights the need to address this gap in the future. This article concludes with consideration of the issues faced and opportunities for overcoming these issues. It is imperative that further work is undertaken on the conceptualization of cyber-wellness and that concensus is developed. There are issues relating to the continual rapid development of techologies and their uses; it is important to develop a shared understanding of the mutual relationship between technology and humans. Finally, there is a lack of guidance and good practice exemplars for cyber-wellness education.
\end{abstract}

Keywords: Cyber-wellness; Digital citizenship; Young people; Digital resilience

\section{Résumé}

Le cyber-bien-être concerne le bien-être (positif) dans les espaces virtuels, y compris la conscience de la façon de se comporter de manière appropriée et de se protéger. Nous expliquons et 
illustrons la nature complexe du cyber-bien-être en nous concentrant sur quatre aspects clés. Tout d'abord, le développement des compétences des élèves en matière d'information et de médias est essentiel pour promouvoir le cyber-bien-être. Ces compétences sont également nécessaires pour soutenir la participation démocratique. Deuxièmement, nous identifions et discutons les menaces et les défis qui pèsent sur le cyber-bien-être des jeunes, en plaidant pour la nécessité de développer la résilience numérique. Troisièmement, nous discutons du rôle des politiques aux niveaux macro, méso et micro et de la manière dont les politiques et les praticiens de l'éducation peuvent promouvoir la sensibilisation, les connaissances et les stratégies en matière de cyber-bien-être. Par la suite, nous passons en revue les quelques études qui ont porté sur l'éducation au bien-être numérique et soulignons la nécessité de combler cette lacune à l'avenir. Nous concluons l'article en examinant les problèmes rencontrés et les possibilités de les surmonter. Il est impératif que des travaux supplémentaires soient entrepris sur la conceptualisation du cyber-bien-être et qu'un consensus se dégage. Il existe des problèmes liés aux développements rapides et continus des technologies et de leurs utilisations ; il est important de développer une compréhension commune de la relation mutuelle entre la technologie et les humains. Enfin, il y a un manque d'éléments-guides et d'exemples de bonnes pratiques pour l'éducation au cyber-bien-être.

Mots clés : Cyber-bien-être ; Citoyenneté numérique ; Jeunes ; Résilience numérique

\section{Introduction}

Cyber-wellness may be defined as "the positive well-being of Internet users and a healthy cyber-culture for the Internet community" (Putnam \& Pulcher, 2007, p. 73). Cyber-wellness involves an understanding of online behaviour and keen awareness of how to inform and protect oneself in cyberspace. It concerns identity, safe and responsible use, and managing online relationships. Cyberwellness focusses on helping students become responsible digital learners and citizens and having positive experiences online. Given the broad reach of the World Wide Web and the access to children that it provides, information and media literacy and awareness of the potential dangers inherent in participating in that environment has become increasingly important (De Paor \& Heravi, 2020). Ensuring that young people develop a deep understanding of the importance to take responsibility for their online safety (including how their online behaviour and activity affects both oneself and others) and developing skills to critically assess online information, will be essential for improving cyber-wellness moving forward.

There is a need for freedom to socialize virtually, obtain information as required (e.g., mental and physical health), and to freely engage in political processes. It also requires a degree of cyberetiquette, responsibility, and civility in the virtual public sphere. Searson et al. (2015) define global or digital citizenship as "a person who develops the skills and knowledge to use the Internet effectively and other digital technology especially in order to participate responsibly in social and civic activities." Searson continues by adding digital communication and collaboration, etiquette, health and welfare, and respecting rights and acting responsibly as components of global digital citizenship. This definition offers a good starting point, but one challenge may be reaching consensus on a definition of "effectively" and "responsibly." 
In this paper, we consider four key aspects that shape the development of cyber-wellbeing. Firstly, we argue that it is essential to develop students' information and media literacy skills and consider the role of this in supporting democratic participation. Secondly, we consider the range of potential threats to young people that they face in online encounters, arguing for the need to develop digital resilience. Thirdly, we discuss the role of policy and how it can promote cyber-wellness awareness, knowledge, and strategies. Finally, we review the limited scholarship in cyber-wellness education and highlight the need to address this gap in the future. We conclude the article with consideration of the issues faced and opportunities for overcoming these.

\section{Cyber-Wellbeing Requires Development of Information and Media Literacy}

Information literacy and media literacy have increased in importance since the turn of the century given increasing access to the Internet (Eisenberg et al., 2004; Livingstone, 2003; McCabe \& Emery, 2003). However, most young people have not yet developed advanced information literacy skills that enable them to judge whether or not information obtained online is reliable (Bartlett \& Miller, 2011; Larson et al., 2018). Furthermore, there are digital divide concerns attributable to differences in national adoption of technology, socio-economic status of students, and individuals' level of use (Ainley, 2018). Fake news, echo chambers, and political manipulation all provide a challenge to information literacy (Kimmons \& Bellikov, 2018; Law et al., 2018). Thus, students can present work based on misinformation and propaganda (Bartlett \& Miller, 2011).

It is essential to develop students' information and media literacy skills, such as critical thinking, in school contexts (Bartlett \& Miller, 2011; Majid et al., 2016; Kimmons \& Belikov, 2018). Thus, teachers must have appropriate knowledge of these skills and how best to teach them (Majid et al., 2016; Passey et al., 2018). Although some national policies mandate this approach, for example in Singapore, there can still be huge variation in students' experiences and skill levels across different schools (Majid et al., 2016; Majid et al., 2020). Furthermore, students may have different levels of expertise. Girls had higher levels of information literacy skills than boys in a recent study in Singapore, and students without home access to the Internet (who we might assume were from more disadvantaged homes) had lower levels than those with access (Majid et al., 2016; Majid et al., 2020).

Social media is a place of ambiguity, being both a public sphere embracing free discourse and a closed community amplifying homogeneous opinion (Mihailidis \& Viotty, 2017; Lazer et al., 2018). This starting point frames our discussion of how to enable young people to be able to recognize both the possibilities and risks that can arise. For example, Jang and Kim (2018) argue that media literacy education could provide an alternative to media regulation to help individuals determine the reliability and validity of information on the Internet. Lazer et al. (2018) point out that combining structural solutions to avoid exposure of individuals to fake news and empowering individuals to evaluate the fake news through media literacy education may be our best strategy to address the challenge.

It is argued that media literacy education should facilitate young people's democratic participation. Phang and Schaefer (2009) assert that media literacy education must address not only creative production but also critical consumption. Mihailidis and Viotty (2017) argue that critical 
media literacy is essential to ensure media consumers do not develop partisan attitudes and mutual distrust. Adult guidance in critical media literacy is key to engaging young people in more diverse communication and fostering political participation.

Widespread social isolation and shelter-in-place policies brought about by the COVID-19 global pandemic have highlighted ordinary citizens' increasing reliance on digital media as their primary source of information. However, the validity and veracity of information conveyed through digital media has become increasingly suspect. Lacking any semblance of the journalistic integrity that was espoused by traditional news media, the Internet has enabled everyone to disseminate information to massive audiences without thought of the validity, veracity, or meaning in the original context. This provides a myriad of opportunities for those who want to use the media to their advantage by stirring up public anxiety and hostility (Pazzanese, 2020).

Responsibility for determining the validity and integrity of information has shifted to the information consumer. Unfortunately, this shift has resulted in a relativistic stance prevailing among such consumers, which asserts truth is merely subjective. As Lewandowsky et al. (2017) argue, humans are experiencing a post-truth world where conventional criteria of evidence, internal consistency, and fact-seeking have been abandoned in exchange for finding the "reality" that each person wants to see in the media. In such a world, when deciding on the "correctness" of information from the media, information consumers must become wary of the danger of basing their decision on similar information from the same kind of favorable media. Otherwise, it will be difficult for the consumers to push themselves out of their comfort zone and consider information that does not accord directly with their own views (Lewandowsky et al., 2017).

\section{Helping Young People Feel Safe in the Digital World}

Threats to young people's cyber-wellness can occur when they purposefully or inadvertently access or post inappropriate information, or when others target young people. Livingstone et al. (2015), Mark and Ratliffe (2011), and Cohen-Almagor (2018) identified risks encountered by children including receiving sexual messages, online contact with strangers, face-to-face meetings with such strangers, harmful content, misuse of personal data, cyber-bullying, and suicide related to cyber-bullying. These threats are summarized in Figures 1 and 2, both in relation to their activities online and by being targeted by online predators.

Levels of awareness of these dangers are commonly investigated. For example, Edwards et al. (2018) focused on young children's (4-5 years old) perception of the Internet. The authors claim that, since children of this age are now able to go online at home without parental support (for example, due to touch screen technologies which make independent use easier), they are susceptible to dangers ranging from "responding inadvertently to inducements for online or in-app purchases" to "experiencing inappropriate content" or "engaging in contact with unknown people" (p. 47). It is argued that young children are not able to contextualize or conceive of these dangers (Edwards et al., 2018). In contrast, participants aged 8-18 (Zilka, 2017) showed a medium-high level of awareness of the dangers of the Internet. The importance of children's awareness for fostering greater cyber-safety has implied a need for new education programs congruent with the rapid evolution of contemporary childhood experiences. These programs should include children in pre-school contexts as this group is least aware of the dangers of the Internet. In addition, given the vulnerability of such young children, it is imperative to ensure that parents can also be supported to educate their children. For 
example, in the UK many schools and organizations (e.g., Internet Matters) provide guidance for parents of early years children.

\section{Figure 1}

Threats to Child Cyber-Wellness as Agent

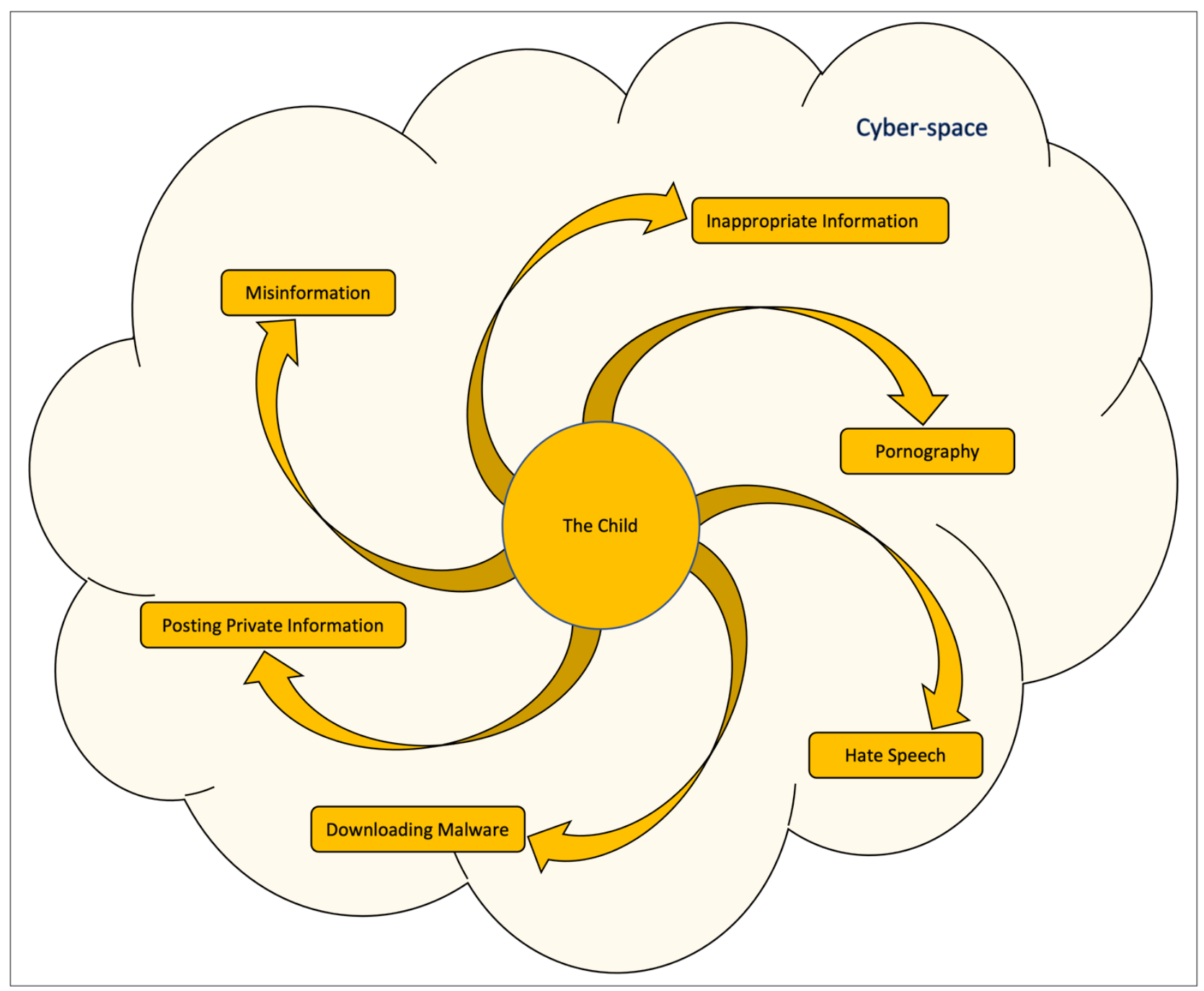

Figure 1 illustrates some of the dangers that a child may encounter in cyber-space.

The anxiety caused by widespread media exposure to online dangers has often led governments to adopt hasty solutions that end up trying to "control" young children rather than to guide them (Facer, 2012). Such attitudes may lead to practices of "over-blocking" through Internet filters, implying a culture that is reactive rather than proactive (Hope, 2008). One could draw a parallel between this kind of censorship and the act of "over-scaffolding" or "over-scripting" which may reduce natural interaction and induce passive learning in literacy education (Vogel et al., 2017; Dillenbourg, 2002; Daniel et al., 2016).

Reactive, top-down approaches may become problematic when state actors or decision makers respond exclusively to demands from their constituency or voter base. States themselves can become cyber-threats to groups or individuals who are not perceived to be supporters or members of one's constituency. For example, members of minority groups may face discrimination or human rights abuse by means of social media tools (Lee, 2019). In the case of the Rohingya crisis in 
Myanmar, it was state actors and state media who perpetuated messages of hate toward the Rohingya ethnic minority through Facebook. In this case, the availability of a social media platform facilitated forced exodus and genocide (Lee, 2019). Ultimately, online racism and discrimination not only harm children psychologically but also worsen their quality of life and the quality of life of their family within a society.

\section{Figure 2}

\section{Threats to Child Cyber-Wellness as Target}

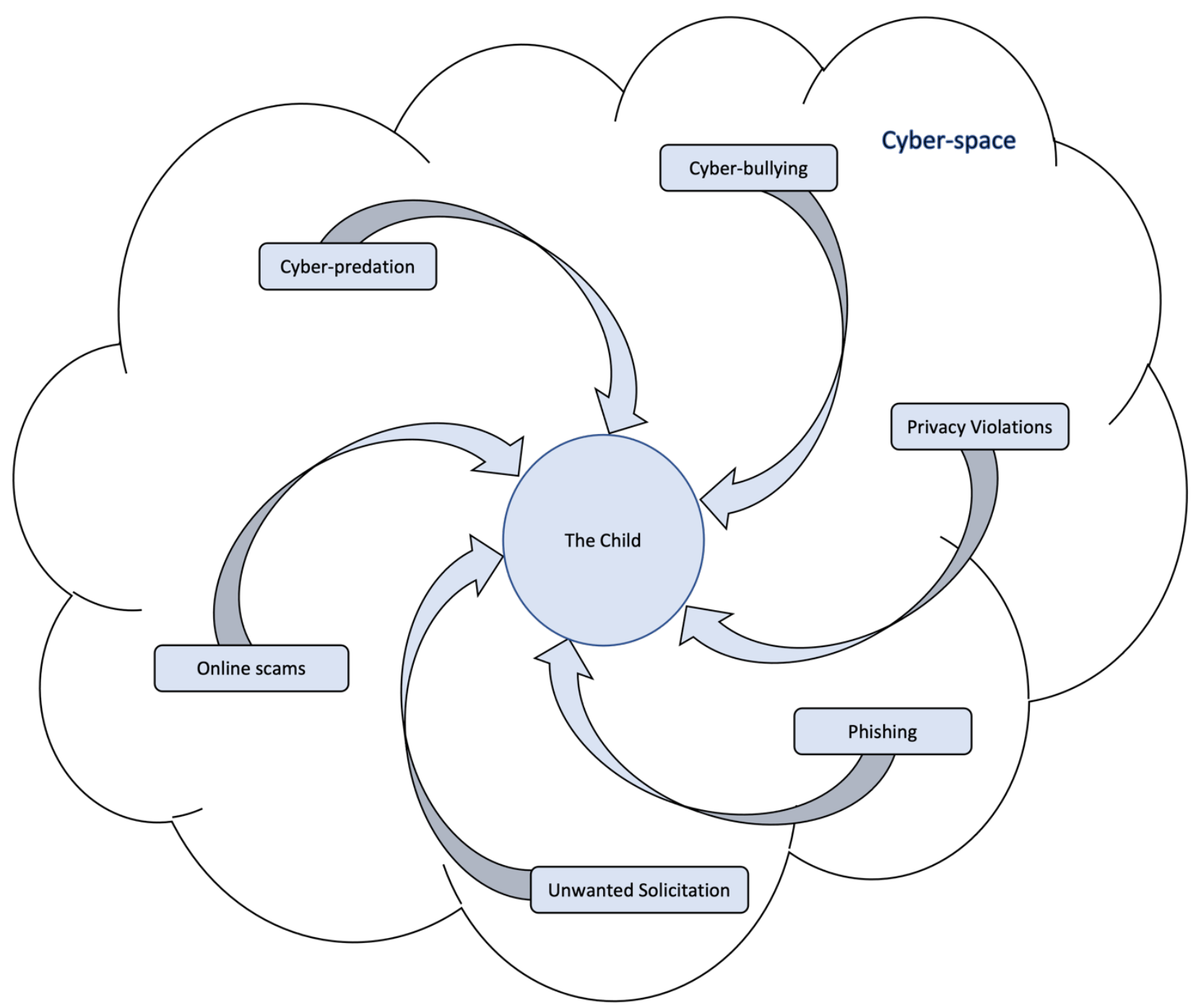

Figure 2 illustrates some of the dangers that a child may encounter from cyber-space.

In developing cyber-wellness strategies to raise awareness of cyber-threats, we must consider the competing political interests and the role of the media in the digital sphere, acknowledge children as agents and citizens in our society, and strike a fine balance between techno-optimism and technoparanoia (Facer, 2012; Davies, 2011). Edwards et al. (2018) propose that educators should seek to understand and build on what children already know about the Internet. In their assessment of Estonian e-safety programs, Lorenz et al., (2012) assert that schools need to move beyond technical regulation-based solutions to more explicit comprehensive training; for example, teaching a child how to change his or her security settings, or what to do when one sees someone being cyber-bullied (Lorenz et al., 2012). 
Beyond considerations for e-safety policies, more concrete practices have been proposed. One notable intervention presented a simulated social networking site (SNS) profile containing risky or dangerous indicators (Vanderhoven \& Schellens, 2015). Students answered questions pertaining to the simulated profile and compared it to their own SNS profiles. Thurlow (2009) proposes the use of specific websites designed for education. The Learning Portal (2019) is just one example of the many websites that teach digital literacy and explain how to behave safely and responsibly on the Internet. Similarly, DQ World (n.d.), a collaboration between Singapore, Korea, and the US, provides resources for children aged 8-12 targeting eight digital citizenship skills which include management of privacy, cyber-bullying, cyber security, and online identity. The 5Rights Foundation (n.d.) has led several projects in which children investigate issues related to cyber-safety and participate in defining their rights in the digital age. Inclusive strategies are also promoted by Audet et al. (2019), who decree "that students, informed of their right to digital education [should] formulate questions and engage in transformative dialogue." In this way, student participation is a good solution to solve a dizzying array of problems related to cyber-wellness.

There is also a growing interest in the development of digital resilience to counter threats to cyber-wellness such as cyber-bullying. The Cyberbullying Research Centre defines digital resilience as "positive attitudes and actions in the face of interpersonal adversity online" (Hinduja, n.d.). A study of 1205 young people aged between 12 and 17 in the US suggests that "students with higher levels of resilience were less likely to report that they had been bullied at school or online" (Hinduja \& Patchin, 2017: p. 57). A Dutch study of college students trained teachers to deliver a digital resilience curriculum, specifically targeting issues of grooming and radicalization (Reynolds \& Parker, 2018). The authors concluded that the project increased "students' sense of responsibility for their actions online, as well as their self-reported knowledge on a range of topics that are critical to safe and resilient use of the Internet" (Reynolds \& Parker, 2018, p. 5).

During the COVID-19 pandemic in 2020, there has been a growth in abusive and violencerelated messages shared through social media, increasing the prevalence of such threats to cyberwellbeing for young people through exposure as well as targeted approaches (Babvey et al, 2020). Considering what we have touched on, three pertinent and timely strategies could be: 1) to help students identify problems and dangers that affect them; 2) to support students in creating and designing their digital sphere (social spaces, tools, legal frameworks); and 3) to develop their "digital resilience."

\section{Promoting Cyber-Wellness Through Policies at a Macro-, Meso-, Micro-Level}

In this section, we provided a nuanced perspective of how policy development can provide support for cyber-wellness. Cyber-wellness is a facet of cyber or digital citizenship, within the larger frame of a global socio-critical perspective or within the context of culture, politics, and civil society (Ntebutse \& Collin, 2018).

In 2016, a United Nations Department of Public Information convention was held in Korea (United Nations, 2016). The outcome of this convention was an initiative titled A Global Day of Education which emphasized education, learning and literacy as a means of supporting global development, peace, and democratic practice. This initiative is in keeping with the United Nations' sustainable developmental goals, especially SDG 4 which emphasizes quality education for all, and historically with article 19 of the 1948 United Nations Declaration of Human Rights. 
Attempting to place cyber-wellness and digital citizenship within a larger global and cosmopolitan context is an attempt to situate these constructs in a matrix of intersecting and potentially conflicting variables. Searson et al. (2011) raise a salient point regarding the degree to which the development of cyber-wellness and cyber-citizenship is limited by national-state identity. This begs the question of whether cyber-wellness, as a component of digital citizenship, should be subsumed under the umbrella of civil rights or human rights. Furthermore, does the constituent power to develop substantive policies addressing cyber-wellness and cyber-citizenship lie within the domain of a new international cosmopolitan order or reside within sovereign location-bounded states?

At a meso level of analysis, each of us develops a personal understanding of the world and our place within it. Given the multitude of social and cultural contexts around the world, there is no common standard for appropriate and rational behavior in the virtual public sphere. Each of us uses multiple ideological surround models (ISM) to craft our understanding of the world and our place within it. Advocates of different ISMs may lack a common standard of evaluation that enables them to agree with us as to what is appropriate and rational behavior in the virtual public sphere. The task is to move beyond this postmodern relativistic stance, and towards a common and agreed ethos of cyber-wellness and digital citizenship.

Furthermore, the open nature of the Internet does not allow for control over the information that is posted, so disparate world views are bound to come against each other. The question is, how do we move beyond this relativistic frame to a common and agreed global ethos of cyber-wellness and digital citizenship? Since we cannot control information on the Internet, the development of globally acceptable cyber-wellness norms will need to focus on the user, with self-restraint replacing external constraints. This leads us to a view of cyber-wellness that is teachable and navigates the channel between relativism and the human right to seek, receive, and impart information in a selfmonitored and civil virtual public sphere.

At the micro level, our task is to educate students so that they can safely and equitably participate in online communities, and that this participation is viewed as essential to a student's development in our global society. There is considerable literature that advises us on how and what to teach students in a way that fosters cyber-wellness and a healthy sense of digital citizenship (see Law et al., 2018; Cooney et al., 2018; Hui \& Campbell, 2018). The technical and educational tools are already available in virtual schooling programs whereby classrooms from opposite sides of our globe can have an opportunity to develop relationships, viewpoints, and conversations in a virtual safe place. The task for policy development is to provide sustainability and capacity to ensure that a virtual global educational process is integrated as part of a student's ongoing educational experience.

To summarize, the first issue to be addressed under policy can be stated simply: should cyberwellness as a component of digital citizenship be subsumed under the umbrella of civil rights or human rights and secondarily, does the constituent power to develop the substantive policies addressing cyber-wellness and cyber-citizenship lie within the domain of a new international cosmopolitan order or sovereign location-bounded states? The second or meso level issue or challenge in creating a policy for cyber-wellness must address how to develop an agreed policy of cyber-wellness that is teachable and navigates the channel between relativism and the human right to seek, receive, and impart information in a self-monitored and civil virtual public sphere. The third 
challenge for policy development is to provide sustainability and capacity to ensure that a virtual global educational process is integrated as part of a student's ongoing educational experience.

\section{Developing Cyber-Wellness Through Teaching and Learning}

Cyber-wellness education is being provided in the world but, unexpectedly, there is little research on innovative practices and their effects. Such empirical research has been conducted mainly in the fields of global digital citizenship education through online international communication and the prevention of cyber-bullying (Li, 2008; Hutson et al., 2018). Very limited research can be found in other fields. One reason for the scarcity of empirical research might be that the innovative practices that researchers are interested in are rare in the field of cyber-wellness or digital citizenship. Another possible reason is the difficulty of evaluating appropriate behaviour. Either way, it is essential that more evaluation research on the practice of cyber-wellness or digital citizenship teaching is conducted, and the findings are shared. It will be important to identify what students know about these issues through surveys and interviews. In addition, innovative practices should be identified and evaluated through observations of practice and eliciting the perceptions of all stakeholders.

The limited research that has been conducted in this area addressed issues like growing students' global digital citizenship through online international communication. For example, Larson et al. (2018) found that sixth graders in the USA and Ireland developed heightened levels of global awareness and diverse perspectives through their activities in an online literature circle. In addition, Fauville et al. (2016) reported on high school students' uses of a carbon footprint calculator followed by discussing the results of each country through online international communication, and consequently found that there was a shift of focus between local and global perspectives (Kumpulainen et al., 2018). Engel et al. (2016) conducted four case studies of US districts' approaches to global citizenship education illustrating innovative practices such as partnering with schools abroad and concluded that provision is diverse at local levels. Finally, Truong-White and McLean (2015) explored the use of digital storytelling in middle and high schools to support global citizenship education. They found that it enhanced student reflection and engagement but did not reach far enough in relation to dealing with controversial issues and determining the underlying causes and impact of global problems.

Secondly, there are many studies on cyber-bullying in which the effects of interventions designed to address this are evaluated. Hutson et al. (2018) conducted a systematic review of such studies and found decreasing effects on cyber-bullying and cyber-victimization were shown for 9 and 10 prevention programs out of 17 , respectively. NoTrap ( $3^{\text {rd }}$ edition) (Palladino et al., 2016) and the ViSC Social Competence Program (Gradinger et al., 2016) were interventions shown to have longlasting effects on both cyber-bullying and cyber-victimization. NoTrap focuses on encouraging young people to support and defend victims, partly drawing on a peer-led model of instruction. The ViSC Social Competence Program is a complex initiative which includes teacher training, meetings with parents, takes place over one year, and targets both teachers and students. Gradinger et al. (2016) were unable to determine the mechanism for change in their study due to this complexity.

Thirdly, Matsuda et al. (2012) developed three-dimensional virtual reality materials which provided students with analytical problems and feedback according to their ability to understand cyber-ethical codes. However, the use of technology to support cyber-wellness through teaching and 
learning is unexpectedly rare, a surprising finding when technology continues to evolve and pervade our daily lives.

\section{Issues and Opportunities}

To promote and develop cyber-wellness, we need to look beyond schooling to consider informal as well as formal learning contexts. We need to be aware of the multiple stakeholders involved, from teachers and parents to community members and commercial technology providers. A key aim should be to instill a healthy scepticism in our youth and ensure that they are proactive in protecting themselves. Young people need to be empowered through the development of resilient attitudes and skills, through experience, risk-taking, and failure. Thus, protecting children from the dangers of the Internet by filtering information, we argue, will not allow them to develop the skills they will need to protect themselves.

Attention needs to be paid to ensuring that all members of our society are equipped to deal with threats to cyber-wellness and make the most of opportunities. However, differences in the awareness and interest in cyber-wellness have already been highlighted. Students in Singapore (where cyber-wellness education is part of the curriculum) without home access to the Internet were less concerned about issues of privacy and cyber-bullying than those with access (Majid et al., 2016; Majid et al., 2020). Interestingly, there were gender differences with females expressing greater concern than males.

We propose that there are three sets of issues that need to be considered in order to promote cyber-wellness and ensure that young people are equipped to deal with any challenges they face in online encounters.

Our first concern relates to the conceptualization of cyber-wellness. The focus is on cyberwellness when it should be on wellness more broadly. Cyber-wellness is a component of wellness. We need to develop a more sophisticated, nuanced, and conceptualized understanding of cyberwellness and its elements or characteristics together with its link to wellness. We need to convince others of the importance and value of the idea of overall wellness.

Secondly, we suggest that technology development poses some challenges. Rather than being focused on the cyber-wellbeing of the learner, the role of technology in education systems is often driven by outside forces (commercial interests, government entities, political interests, propaganda, etc.). Furthermore, developments in technology are presenting threats to maintaining cyber-wellness (e.g. increasing surveillance, managing students' personal behavior, big data and learning analytics, artificial intelligence). The challenges arising from these socio-technical trends need to be addressed.

Thirdly, there are issues that relate to cyber-wellness education. We lack guidance, training, and tools for practitioners that are grounded in theory. Current school curricula internationally do not effectively integrate well-being. The focus tends to be on setting limits and regulation, rather than focusing on a strength-based approach that encompasses balanced skill-building towards empathy, compassion, self-regulation, self-awareness, community awareness, and support structures. More broadly, we need diverse, flexible, and sustainable practices to support the development of cyberwellness across learning environments within social contexts in a civil society (cultures, socio- 
economic backgrounds, ideologies, etc.). We need to take account of different levels of experience of information literacy and develop a deeper understanding of differences according to factors such as gender and socio-economic status. Cyber-wellness educators would be better equipped to ensure that all young people benefit from programs designed to develop information literacy, digital citizenship skills and digital resilience, irrespective of their background, access to resources and prior experiences. We have identified the following opportunities for addressing the issues identified above.

A consensus on a concise definition of wellness and cyber-wellness (social, psychological, physical, and cognitive) needs to be developed there needs to be an increased awareness of the fact that cyber-wellness is part of overall wellness.

In relation to technology, we need to create an understanding of the mutual relationship between technology and humans; we are shaping the technologies that we use and the technologies that we use are shaping us and the way that we live our lives in a digital society. Moreover, we need to establish an ongoing cycle of evaluation of the technologies that we use. We also need to promote self-awareness of how we learn and are influenced by technology. The development of a community of stakeholders for discussing and determining the proper use of technology would also be beneficial.

To develop cyber-wellness education stakeholders should be encouraged to integrate wellness across curricula. A balance needs to be created between learning opportunities and use of protocols (driven by e-safety concerns, for example) in cyber-wellness education. It is important to encourage educators to take more responsibility for developing these practices. Educators have the expertise and knowledge required to develop effective practices for cyber-wellness education. In addition, young people should be more involved in designing and conducting research and informing policy and practice in this field.

Finally, a few thoughts about the challenges presented to policy development and, more importantly, to implementation by the intersect in our postmodern society of radical individualism and the age of authenticity. Most noticeable since the 1960s, civil society has been faced by an obsession with being true to oneself; being authentic. The seeking of authenticity and sincerity has for some been criticized as leading to a corrosion of all forms of collective authority. Radical individualism (personal priorities over society priorities) can be seen in the refusal to wear masks, socially isolate, or even believe there is a pandemic (Steig, 2020; Walsh, 2020). Epistemology asks us to think about the social conditions that create our knowledge foundations. If society is adhering to the ideological surround model of authenticity and radical individualism, how do we as educators gain support and inculcate in our students the collective sense of responsibility that is necessary for civility, toleration, and an equitable version of digital citizenship?

Cyber-wellness is an issue that has become incredibly complex in a very short period of time so blind spots are unavoidable. Arguably, it has become increasingly important during the pandemic due to young people's increased online activity, and well-being has been brought to the fore in challenging times. However, there remains a need to index rigorously the entirety of cyber-issues and their possible solutions so that interlocutors can easily reference and improve pertinent ideas.

Furthermore, better channels of communication must be forged so that the transformative dialogue of cyber-wellness negotiation is preserved. 


\section{References}

Ainley, J. (2018). Students and their computer literacy: Evidence and curriculum implications. In J. Voogt, G. Knezek, R. Christensen, \& K.-W. Lai (Eds.), Second handbook of information technology in primary and secondary education (pp.69-88). Springer. https://doi.org/10.1007/978-3-319-53803-7

Audet, L., Boulay, M.-F., Camara, D., Doyon, J., Johnson, Q., Laferrière, T., Mazerolle, A., \& Suarez, L. (2019, April 3). Declaration of principles regarding the right to digital education. https://www.tact.ulaval.ca/sites/tact.ulaval.ca/files/declaration of principles regarding the $\mathrm{r}$ ight to digital education 2704 2019.pdf

Babvey, P., Capela, F., Cappa, C., Lipizzi, C., Petrowski, N., \& Ramirez-Marquez, J. (2020). Using social media data for assessing children's exposure to violence during the COVID-19 pandemic. Child Abuse \& Neglect, 116(20), 1-14. https://doi.org/10.1016/j.chiabu.2020.104747

Bartlett, J., \& Miller, C. (2011). Truth, lies and the Internet: A report into young people's digital fluency. Demos. https://dera.ioe.ac.uk//23204/

Cohen-Almagor, R. (2018). Social responsibility on the Internet: Addressing the challenge of cyberbullying. Aggression and Violent Behavior, 39, 42-52. https://doi.org/10.1016/j.avb.2018.01.001

Cooney, C., Nugent, K., \& Howard, K. G. (2018). Embedding digital citizenship in higher education institutions. All Ireland Journal of Higher Education, 10(2), 360.1-360.8. http://ojs.aishe.org/index.php/aishe-j/article/view/360/594

Daniel, S. M., Martin- Beltrán, M., Peercy, M. M., \& Silverman, R. (2016). Moving beyond yes or no: Shifting from over- scaffolding to contingent scaffolding in literacy instruction with emergent bilingual students. TESOL Journal, 7(2), 393-420. https://doi.org/10.1002/tesj.213

Davies, R. (2011). Understanding technology literacy: A framework for evaluating educational technology integration. TechTrends, 55(5), 45-52. https://doi.org/10.1007/s11528-011-0527-3

De Paor, S., \& Heravi, B. (2020). Information literacy and fake news: How the field of librarianship can help combat the epidemic of fake news. The Journal of Academic Librarianship, 46(5), 1-8. https://doi.org/10.1016/j.acalib.2020.102218

Dillenbourg, P. (2002). Over-scripting CSCL: The risks of blending collaborative learning with instructional design. In P. A. Kirschner (Ed.), Three worlds of CSCL. Can we support CSCL? (pp. 61-91). Open University. https://telearn.archives-ouvertes.fr/hal-00190230/

DQ World (n.d.). DQ World. https://us.dqworld.net/\#!/landing

Edwards, S., Nolan, A., Henderson, M., Mantilla, A., Plowman, L., \& Skouteris, H. (2018). Young children's everyday concepts of the Internet: A platform for cyber-safety education in the early years. British Journal of Educational Technology, 49(1), 45-55.

$\underline{\text { https://doi.org/10.1111/bjet.12529 }}$ 
Eisenberg, M. B., Lowe, C. A., \& Spitzer, K. L. (2004). Information literacy: Essential skills for the information age (2nd ed.). Libraries Unlimited.

Engel, L. C., Fundalinski, J., \& Cannon, T. (2016). Global citizenship education at a local level: A comparative analysis of four U.S. urban districts. Revista Española de Educación Comparada, 28, 23-51. https://doi.org/10.5944/reec.28.2016.17095

Facer, K. (2012). After the moral panic? Reframing the debate about child safety online. Discourse: Studies in the Cultural Politics of Education, 33(3), 397-413. https://doi.org/10.1080/01596306.2012.681899

Fauville, G., Lantz-Andersson, A., Mäkitalo, Å., Dupont, S., \& Säljö, R. (2016). The carbon footprint as a mediating tool in students' online reasoning about climate change. In O. Erstad, S. Jakobsdottir, K. Kumpulainen, Å. Mäkitalo, P. Pruulmann-Vengerfeldt, \& K. Schrøder (Eds.), Learning across contexts in the knowledge society (pp. 179-202). Sense Publishers.

Gradinger, P., Yanagida, T., Strohmeier, D., \& Spiel, C. (2016). Effectiveness and sustainability of the ViSC Social Competence Program to prevent cyberbullying and cyber-victimization: Class and individual level moderators. Aggressive Behavior, 42(2), 181-193. https://doi.org/10.1002/ab.21631

Hinduja, S. (n.d.). Digital resilience. Cyberbullying Research Centre. https://cyberbullying.org/digital-resilience

Hinduja, S., \& Patchin, J. W. (2017). Cultivating youth resilience to prevent bullying and cyberbullying victimization. Child Abuse \& Neglect, 73, 51-62. http://dx.doi.org/10.1016/j.chiabu.2017.09.010

Hope, A. (2008). Internet pollution discourses, exclusionary practices and the 'culture of overblocking' within UK schools. Technology, Pedagogy and Education, 17(2), 103-113. https://doi.org/10.1080/14759390802098599

Hui, B., \& Campbell, R. J. (2018). Discrepancy between learning and practicing digital citizenship. Journal of Academic Ethics, 16(2), 117-131. https://doi.org/10.1007/s10805-018-9302-9

Hutson, H., Kelly, S., \& Militello, L. K. (2018). Systematic review of cyberbullying interventions for youth and parents with implications for evidence-based practice. Worldviews on EvidenceBased Nursing, 15(1), 72-79. https://doi.org/10.1111/wvn.12257

Jang, S. M., \& Kim, J. K. (2018). Third person effects of fake news: Fake news regulation and media literacy interventions. Computers in Human Behavior, 80, 295-302. https://doi.org/10.1016/j.chb.2017.11.034

Kimmons, R., \& Belikov, O. (2018). Cultural and social issues in using social media to support learning. In J. Voogt, G. Knezek, R. Christensen, \& K.-W. Lai (Eds.), Second handbook of information technology in primary and secondary education (pp.181-198). Springer. https://doi.org/10.1007/978-3-319-53803-7 
Kumpulainen, K., Mikkola, A., \& Rajala, A. (2018). Dissolving the digital divide: Creating coherence in young people's social ecologies of learning and identity building. In J. Voogt, G. Knezek, R. Christensen, \& K.-W. Lai (Eds.), Second handbook of information technology in primary and secondary education (pp. 107-119). Springer. https://doi.org/10.1007/978-3$\underline{319-53803-7}$

Larson, L., Forzani, E., \& Leu, D. J. (2018). New literacies: Curricular implications. In J. Voogt, G. Knezek, R. Christensen, \& K.-W. Lai (Eds.), Second handbook of information technology in primary and secondary education (pp. 37-52). Springer. https://doi.org/10.1007/978-3-31953803-7

Law, N., Chow, S.-L., \& Fu, K.-W. (2018). Digital citizenship and social media: A curriculum perspective. In J. Voogt, G. Knezek, R. Christensen, \& K.-W. Lai (Eds.), Second handbook of information technology in primary and secondary education (pp. 53-68). Springer. https://doi.org/10.1007/978-3-319-53803-7

Lazer, D. M. J., Baum, M. A., Benkler, Y., Berinsky, A. J., Greenhill, K. M., Menczer, F., Metzger, M. J., Nyhan, B., Pennycook, G., Rothschild, D., Schudson, M., Sloman, S. A., Sunstein, C. R., Thorson, E. A., Watts, D. J., \& Zittrain, J. L. (2018). The science of fake news. Science, 359(6380), 1094-1096. https://doi.org/10.1126/science.aao2998

Lee, (2019). Extreme speech | Extreme speech in Myanmar: The role of state media in the Rohingya forced migration crisis. International Journal of Communication. 13, pp. 3203-3224. https://www.ijoc.org/index.php/ijoc/article/view/10123

Lewandowsky, S., Ecker, U., \& Cook, J. (2017). Beyond misinformation: Understanding and coping with the "post-truth" era. Journal of Applied Research in Memory and Cognition, 6(4), 353369. https://doi.org/10.1016/j.jarmac.2017.07.008

Li, Q. (2008). Cyberbullying in schools: An examination of preservice teachers' perception. Canadian Journal of Learning and Technology, 34(2), 5-90. https://doi.org/10.21432/T2DK5G

Livingstone, S. (2003). Media literacy and the challenge of new information and communication technologies. The Communication Review, 7(1), 3-14.

https://doi.org/10.1080/10714420490280152

Livingstone, S., Mascheroni, G., Dreier, M., Chaudron, S., \& Lagae, K. (2015). How parents of young children manage digital devices at home: The role of income, education and parental style. EU Kids Online.

http://eprints.lse.ac.uk/63378/1/ 1se.ac.uk_storage_LIBRARY_Secondary libfile shared re pository Content EU\%20Kids\%20Online EU Kids_Online How\%20parents\%20manage\% 20digital\%20devices_2016.pdf

Lorenz, B., Kikkas, K., \& Laanpere, M. (2012). Comparing children's E-Safety strategies with guidelines offered by adults. Electronic Journal of E-Learning, 10(3), 326-338.

Majid, S., Chang, Y.-K., \& Foo, S. (2016). Auditing information literacy skills of secondary school students in Singapore. Journal of Information Literacy, 10(1), 44-66.

https://doi.org/10.11645/10.1.2068 
Majid, S., Foo, S., \& Chang, Y.-K. (2020). Appraising information literacy skills of students in Singapore. Aslib Journal of Information Management, 72(3), 379-394.

https://doi.org/10.1108/AJIM-01-2020-0006

Mark, L., \& Ratliffe, K. T. (2011). Cyber worlds: New playgrounds for bullying. Computers in the Schools, 28(2), 92-116. https://doi.org/10.1080/07380569.2011.575753

Matsuda, T., Nakayama, H., \& Tamada, K. (2012) Using 3D virtual reality technology for cyber ethics education: How can we really evaluate and change the attitude of students? In L. Lennex and K. Nettleton (Eds.), Cases on 3D technology application and integration in education (pp. 439-463). Hershey PA: IGI Global.

McCabe, R., \& Emery, W. (2003). The development of media literacy among grade five teachers and students - A case study. Canadian Journal of Learning and Technology, 29(1). https://doi.org/10.21432/T2FS4G

Mihailidis, P., \& Viotty, S. (2017). Spreadable spectacle in digital culture: Civic expression, fake news, and the role of media literacies in "post-fact" society. American Behavioral Scientist, 61(4), 441-454. https://doi.org/10.1177/0002764217701217

Ntebutse, J. G., \& Collin, S. (2018). A socio-critical perspective on the integration of digital technology in education. In J.Voogt, G. Knezek, R. Christensen, \& K.-W. Lai. (Eds.), Second handbook of information technology in primary and secondary education. Springer. https://doi.org/10.1007/978-3-319-53803-7

Palladino, B., Nocentini, A., \& Menesini, E. (2016). Evidence-based intervention against bullying and cyberbullying: Evaluation of the NoTrap! program in two independent trials. Aggressive Behavior, 42(2), 194-206. https://doi.org/10.1002/ab.21636

Passey, D., Shonfeld, M., Appleby, L., Judge, M., Saito, T., \& Smits, A. (2018). Digital agency: Empowering equity in and through education. Technology, Knowledge and Learning, 23, 425-439. https://doi.org/10.1007/s10758-018-9384-x

Pazzanese, C. (2020, May 8th). Battling the 'pandemic of misinformation'. The Harvard Gazette. https://news.harvard.edu/gazette/story/2020/05/social-media-used-to-spread-create-covid-19falsehoods/

Phang, A., \& Schaefer, D. J. (2009). Is ignorance bliss? Assessing Singaporean media literacy awareness in the era of globalization. Journalism \& Mass Communication Educator, 64(2), 156-172. https://doi.org/10.1177/107769580906400203

Putnam, J., \& Pulcher, K. L. (2007). An E-Learning strategy towards a culture of cyber wellness and health for WMSCI. Journal of Systemics, Cybernetics and Informatics, 5(6), 73-76. http://www.iiisci.org/journal/sci/FullText.asp?var=\&id=S372DT

Reynolds, L., \& Parker, L. (2018). Digital resilience: Stronger citizens online. Institute for Strategic Dialogue. https://www.isdglobal.org/isd-publications/digital-resilience-stronger-citizensonline/ 
Searson, M., Hancock, M., Soheil, N., \& Shepherd, G. (2015). Digital citizenship within global contexts. Education and Information Technologies, 20(4), 729-741.

https://doi.org/10.1007/s10639-015-9426-0

Searson, M., Jones, W. M., \& Wold, K. (2011). Reimagining schools: The potential of virtual education. British Journal of Educational Technology, 42(3), 363-371.

https://doi.org/10.1111/j.1467-8535.2011.01178.x

Steig, C. (2020, September 2). Sociopathic traits linked to not wearing a mask or social distancing during pandemic: Study. CNBC. https://www.cnbc.com/2020/09/02/study-refusal-to-wearface-mask-associated-with-psychopathy-traits.html

The 5Rights Foundation (n.d.). 5 Rights. https://5rightsfoundation.com/about-us/the-5-rights/

The Learning Portal: Digital Citizenship (2019, June 13). https://tlp-lpa.ca/home/digital-citizenship

Thurlow, R. (2009). Improving emergent literacy skills: Web destinations for young children.

Computers in the Schools, 26(4), 290-298. https://doi.org/10.1080/07380560903360210

Truong-White, H., \& McLean. L. (2015). Digital storytelling for transformative global citizenship education. Canadian Journal of Education, 38(2), 1-28.

https://doi.org/10.2307/canajeducrevucan.38.2.11

United Nations (2016, February 5). Republic of Korea to host Department of Public

Information/Non-Governmental Organizations conference in Gyeongju, 30 May-1 June. https://www.un.org/press/en/2016/ngo826.doc.htm

Vanderhoven, E., \& Schellens, T. (2015). How authentic should a learning context be? Using real and simulated profiles in a classroom intervention to improve safety on social network sites. International Journal of Cyber Society and Education, 8(1), 1-18. http://dx.doi.org/10.7903/ijcse.1385

Vogel, F., Wecker, C., Kollar, I., \& Fischer, F. (2017). Socio-cognitive scaffolding with computersupported collaboration scripts: A meta-analysis. Educational Psychology Review, 29(3), 477-511. https://doi.org/10.1007/s10648-016-9361-7

Walsh, C. (2020, August 28). Why some Americans refuse to social distance and wear masks. The Harvard Gazette. https://news.harvard.edu/gazette/story/2020/08/sandel-explores-ethics-ofwhat-we-owe-each-other-in-a-pandemic/

Zilka, G. C. (2017). Awareness of eSafety and potential online dangers among children and teenagers. Journal of Information Technology Education: Research, 16, 319-338. https://doi.org/10.28945/3864 


\section{Authors}

Cathy Lewin is Professor of Education in the Education and Social Research Institute at Manchester Metropolitan University, United Kingdom. She conducts research on digital pedagogy in compulsory education, and young people's uses of technology to support formal and informal learning. Email: c.lewin@mmu.ac.uk

Dale Niederhauser, West Virginia University, USA, has served as president of the ISTE Special Interest Group for Teacher Educators and in leadership roles in the American Educational Research Association and the EDUsummIT. He has taught coursework and conducted research on learning technologies at West Virginia University, Iowa State University, and the University of Utah.

Quinn Johnson completed his masters degree in Educational Technology at Université Laval. He currently works as a pedagogical counsellor at Saint Lawrence College in Quebec City, Canada. He has taught English in Canada, Korea, and Japan. His research interests include the right to digital education, open educational resources, computer assisted language learning, and technopedagogy.

Toshinori Saito is an associate professor of Education and Computing at Seisa University, Japan. As a strong advocate of digital equity and agency, he is an active member of TC3 in IFIP and has been involved in academic research regarding computing education for children and adults in non-formal education areas.

Akira Sakamoto is vice-president and professor of Ochanomizu University located in Tokyo which is the oldest women's university in Japan. He has been teaching social psychology and conducting research on the psychological impact of electric media use for over thirty years.

Roger Sherman, is the director of research for the Cambodian Foundation for Higher Education, USA, currently focusing on the intersect between trauma and education. He is also on the faculty of Simmons College, Graduate School of Social Services, Boston, Massachusetts. His research interests include globalisation, immigration, trauma, mental health and education, alongside virtual learning.

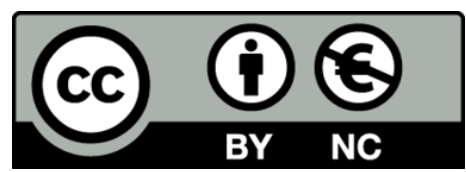

This work is licensed under a Creative Commons AttributionNonCommercial CC-BY-NC 4.0 International license. 